\title{
Development of Machining Processes for the Use of Multilayer High-Performance Coatings
}

\author{
Sebastian Goeke, Tobias Brüggemann, and Dirk Biermann \\ Institute of Machining Technology, TU Dortmund, Baroper Straße 301, 44227 Dortmund, Germany \\ Correspondence should be addressed to Tobias Brüggemann; bruggemann@isf.de
}

Received 12 September 2012; Accepted 13 November 2012

Academic Editors: G. R. Fenske and I. C. Gebeshuber

Copyright (c) 2013 Sebastian Goeke et al. This is an open access article distributed under the Creative Commons Attribution License, which permits unrestricted use, distribution, and reproduction in any medium, provided the original work is properly cited.

\begin{abstract}
The development of corrosion- and wear-resistant high-performance coatings is important to improve components of mobile and stationary turbines, aerospace undercarriages, combustion engines, and hydraulic modules. New micro- and nanostructured coating materials and processes to machine these coatings are developed in order to increase the performance of workpieces and components, to enhance durability, and to reduce maintenance and manufacturing costs. At the Institute of Machining Technology (ISF), milling and grinding procedures have been developed for the preparation of the workpiece surface for the subsequent coating process. In contrast to conventional applications, the workpieces are not manufactured with the aim of achieving a minimized resulting surface roughness. Instead of this, a defined and adequate structure has to be generated, providing a good adhesion of the thermal sprayed coating on the workpiece surface. After first coating of the prepared substrates by a High-Velocity-Oxygen-Fuel (HVOF) coating process, the resulting surface topography does not have the required surface quality for a subsequent (Diamond Like Carbon) DLC coating process. In order to generate a more uniform surface structure, the deteriorated surface resulting from the HVOF coating process also has to be processed. Therefore, the application of an adapted grinding process with diamond wheels is used.
\end{abstract}

\section{Introduction}

To increase the wear, erosion, and corrosion resistance of tribologically stressed functional surfaces, the use of thermally sprayed coatings increases. Typical applications for these slide or bearing surfaces are stationary turbines, aerospace undercarriages, combustion engines, and hydraulic modules [1]. One of these thermal spraying processes is the HighVelocity Oxygen Fuel (HVOF). Based on the high particle velocity a low porosity, high bond strength, and an increased hardness are the main advantages of this thermal spraying process $[2,3]$. In order to obtain a good adhesion between the coating and the substrate, it is necessary to prepare the substrate surface. Although coinciding with several disadvantages, such as the necessity to clean the workpiece and the costs, a blasting process is usually used to activate the surface. In order to circumvent these disadvantages, other machining processes have to be considered. Obtaining unique surface structures which are similar to blasted surfaces regarding the roughness is also possible with other machining processes. These machining processes may be milling, grinding, or honing, for example. Depending on the process parameters, they are able to generate different surface structures, too.

Unfortunately, the surface roughness resulting from the HVOF coating process exceeds the acceptable limit for many applications, especially in case of using multilayer coatings. DLC (Diamond Like Carbon) coatings which are more and more applied by a PVD (Physical Vapour Deposition) process on the tungsten carbide coating have a thickness of less than $5 \mu \mathrm{m}$. In order to gain a more uniform surface structure for a subsequent DLC coating process or to improve the tribological behaviour of the HVOF coating, the workpieces are typically ground $[4,5]$. The HVOF coating material used in this study is a WC-CoCr layer which has been proven for its good performance regarding wear test. Based on this inherent material property, it is a good substitute for hard-chromium coatings which are not favourable due to their toxic production process [6]. Furthermore, multilayer 


\begin{tabular}{|l|}
\hline Milling of X12Cr13 \\
Process dimensions \\
Feed velocity $v_{f}$ \\
Wepth of cut $a_{p}$ \\
Toolth of cut $a_{e}$ \\
Tool cutting edge angle $\kappa_{r}$ \\
Surface quality \\
In the direction of feed motion: \\
$R z=6.3-28.9 \mu \mathrm{m}$ \\
Against the direction of feed motion: \\
$R z=5-32.5 \mu \mathrm{m}$
\end{tabular}
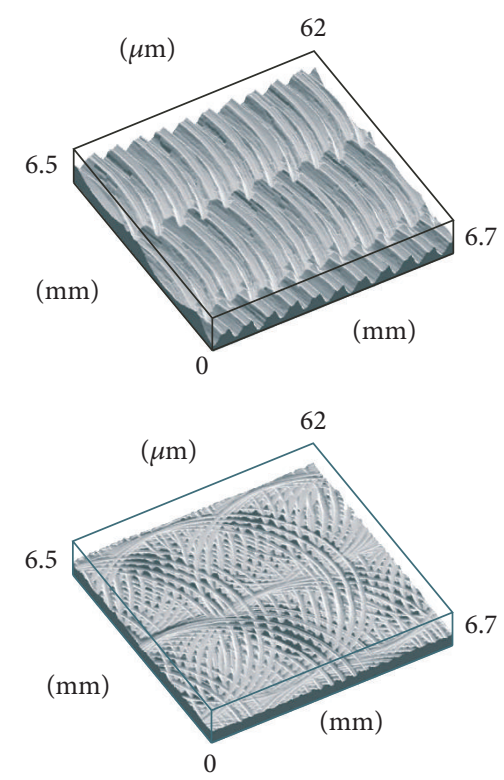
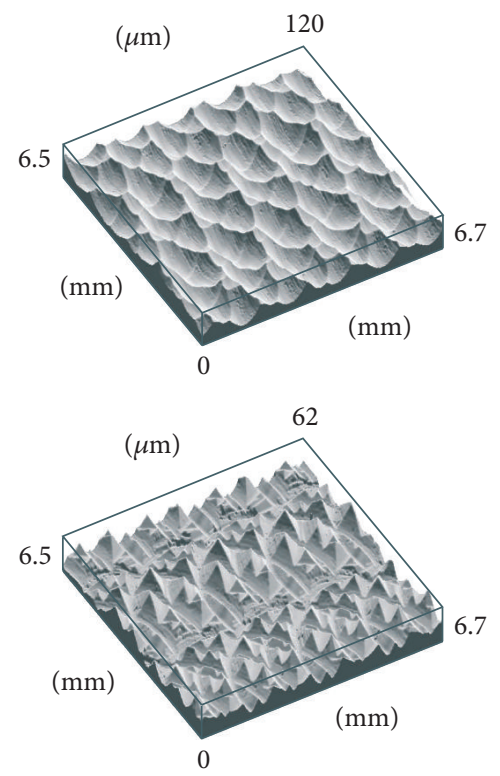

FIGURE 1: Selection of manufacturable surface structures by milling.

systems consisting of tungsten carbide and Diamond Like Carbon are characterized by a singnificantly increased wear resistance and an improved adhesion of the DLC coating compared to single DLC coatings [7].

\section{Preparation of the Substrate Surface}

2.1. Preparation of the Surface Topography by Milling. Before the thermal spraying process, a preparation of the substrate surface is necessary. This is used to activate the surface and to create a defined roughness, thereby a sufficient coating adhesion is guaranteed. For this purpose, milling processes are used because they allow the preparation of almost any surface geometry. The cutting parameters and the contact ratios can be varied. Thereby the structures and the roughness parameters can be modified in relatively wide ranges. With the material X12Cr13, machinability tests were conducted. Figure 1 shows examples of possible surface topographies. These were obtained with a toroidal high-feed milling cutter made by Hitachi with a diameter of $d=10 \mathrm{~mm}$ and a corner radius of $r=2 \mathrm{~mm}$. The representations were created by rendering the digitized data, which were acquired with a confocal measuring microscope. The accompanying software also allows the subsequent extraction of roughness parameters from this data in any direction of the measured surface. The different surface characteristics which are determined by the engagement conditions are clearly visible. This can be obtained by changing the inclination of the milling tool to the surface. The distance between the individual milling scratches can be varied by the feed per tooth and the mutual penetration of the scratches by the width of cut. Due to the small thickness of the tungsten carbide layer of approximately 100 microns or less, finer structures, as shown in the middle of Figure 1, are appropriate for an interface with good adhesion between substrate and coating. Referring to the experiments, the cutting tools show good suitability for machining used test material, even at very high tooth feeds and cutting widths. As expected, by using low-alloy tool steels, a slightly higher tool wear occurred. Furthermore the used tools had a defined tool corner radius and were thereby suitable for the processing of free-form elements. Additionally, they can be used for radial engagement conditions, thus resulting in a greater freedom of surface structure production.

\subsection{Preparation of the Surface Topography by Short-Stroke} Honing. In contrast to the milling process, the aim of the short-stroke honing process, also called microfinishing, is the generation of smooth surface topographies with variable material ratios. The machining kinematic of the finishing process, as shown in Figure 2, is characterized by a superposition of different tools and workpiece motions. The tangential motion is realized by a rotating workpiece. It has the most significant influence on the cutting velocity, while the axial velocity which is generated by the oscillating finishing tool has a less significant influence on the cutting velocity. Nevertheless, the axial motion is needed to obtain a smooth surface topography without profile peaks and variable profile valleys. The contact between the finishing tool and workpiece is guaranteed by the infeed force which has a substantial influence on the generated surface topography as well as the machining time and the grain size of the finishing film $[8,9]$. By using finishing films with different grain sizes and bond structure in subsequent process steps, a specific surface structure regarding the peak height and valley depth occurs [10-12].

In order to generate different surface structures, two types of finishing films have been used. On the one hand, an electrostatic adjusted finishing film with a grain size of $d_{K}=$ $30 \mu \mathrm{m}$ and on the other hand muddled finishing films with a grain size of $d_{K}=30,9$, and $3 \mu \mathrm{m}$. As shown in Figure 2 these 
Process model

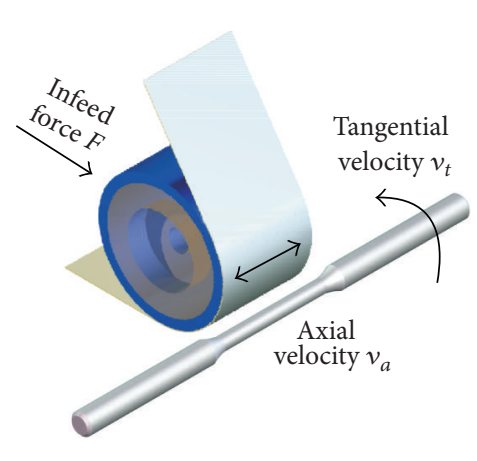

Process steps

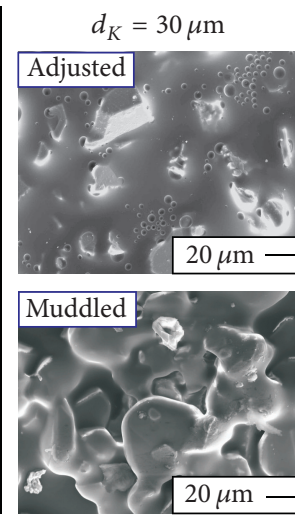

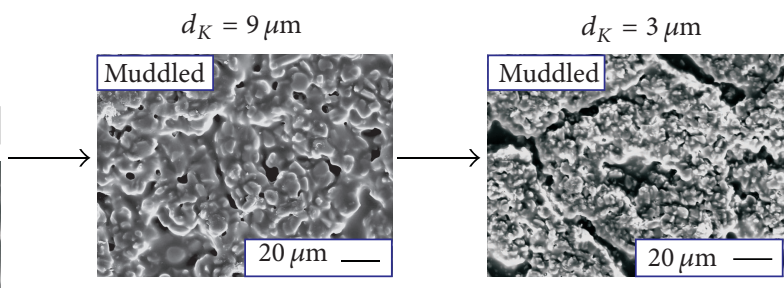

FIGURE 2: Microfinishing: process model and process combinations.

\begin{tabular}{|c|c|c|c|c|}
\hline Material & Grain type & Grain size & Infeed force & Process time \\
\hline $100 \mathrm{Cr} 6$ & $\mathrm{Al}_{2} \mathrm{O}_{3}$ & $d_{K}=30 ; 9,3 \mu \mathrm{m}$ & $\begin{array}{l}F(30 \mu \mathrm{m})=120 \mathrm{~N} \\
F(9 ; 3 \mu \mathrm{m})=120 \mathrm{~N}\end{array}$ & $\begin{array}{l}t=20 \mathrm{~s} \\
t_{\mathrm{Ges}}=60 \mathrm{~s}\end{array}$ \\
\hline
\end{tabular}
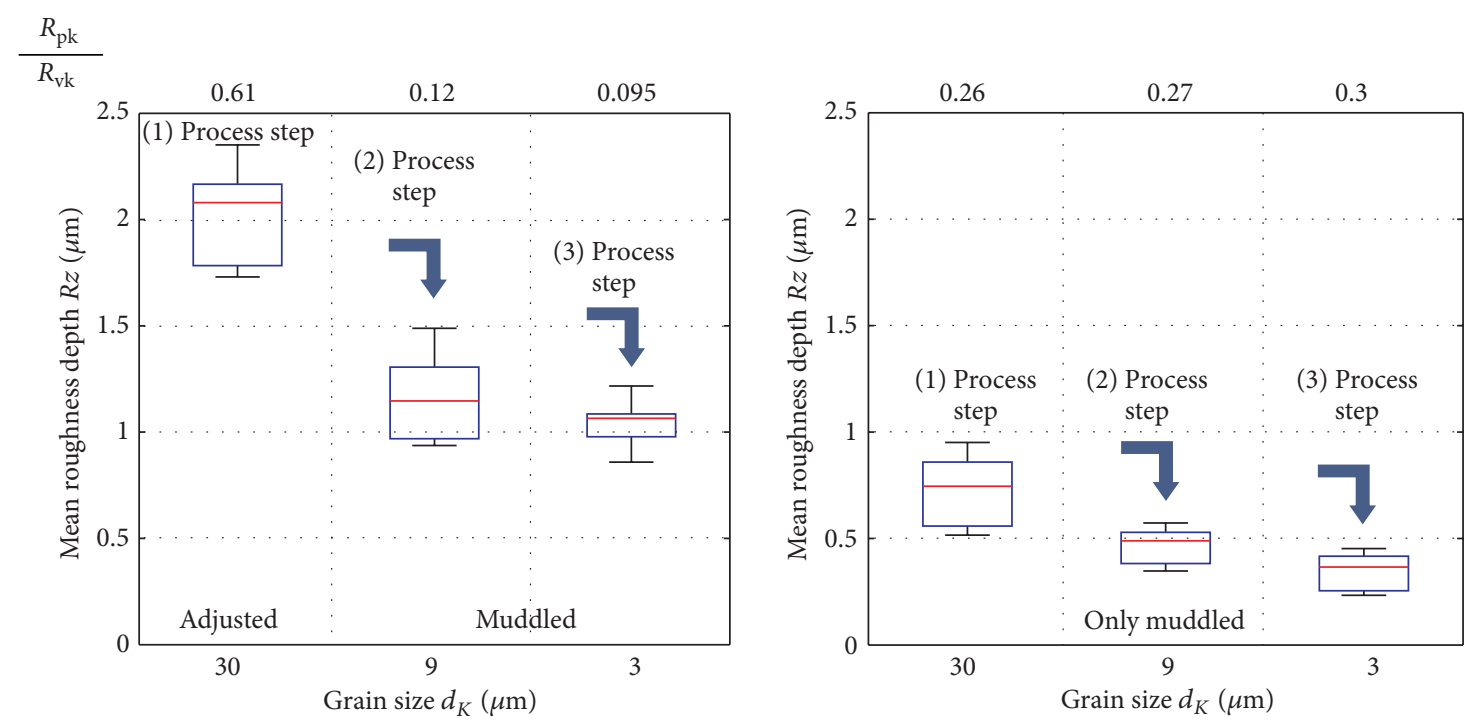

FIGURE 3: Microfinishing of the substrate- surface roughness.

finishing films have been combined in two different process strategies.

The type of premachining $\left(d_{K}=30 \mu \mathrm{m}\right)$ has a significant influence on the resulting surface topography. By using an electrostatic adjusted finishing film, an aggressive machining process occurs because of the sharp grain edges which reach out of the bond. As shown in Figure 3, after the first process step with an adjusted finishing film and a machining time of $t=20 \mathrm{~s}$, a mean roughness depth of $R z=2 \mu \mathrm{m}$ occurs. By using two subsequent finishing steps with a grain size of $d_{K}=9 \mu \mathrm{m}$ and $d_{K}=3 \mu \mathrm{m}$, the mean roughness depth can be decreased to $R z=1 \mu \mathrm{m}$. Regarding the tribological behaviour of the surface, it is insufficient to classify the surface topographies only by the mean roughness depth $[13,14]$.
A surface with an increased peak height and a low valley depth probably will have the same mean roughness depth as a surface with low peak height and increased valley depth. To describe the differences between the generated surfaces in detail, the relation between peak height and valley depth can be used. As shown in Figure 3, the typical surface topography generated by microfinishing is characterized by a greater valley depth compared to the peak height $(R \mathrm{pk} / R \mathrm{vk}<1$ for all finishing steps). Using a combination of adjusted and muddled finishing films leads to an increased valley depth on the surface topography because the muddled finishing films with smaller grain sizes are just decreasing the peak height. Accordingly, after a three-process steps, a plateau-like surface occurs with peak/valley relation of $R \mathrm{pk} / R \mathrm{vk}<0.1$. 


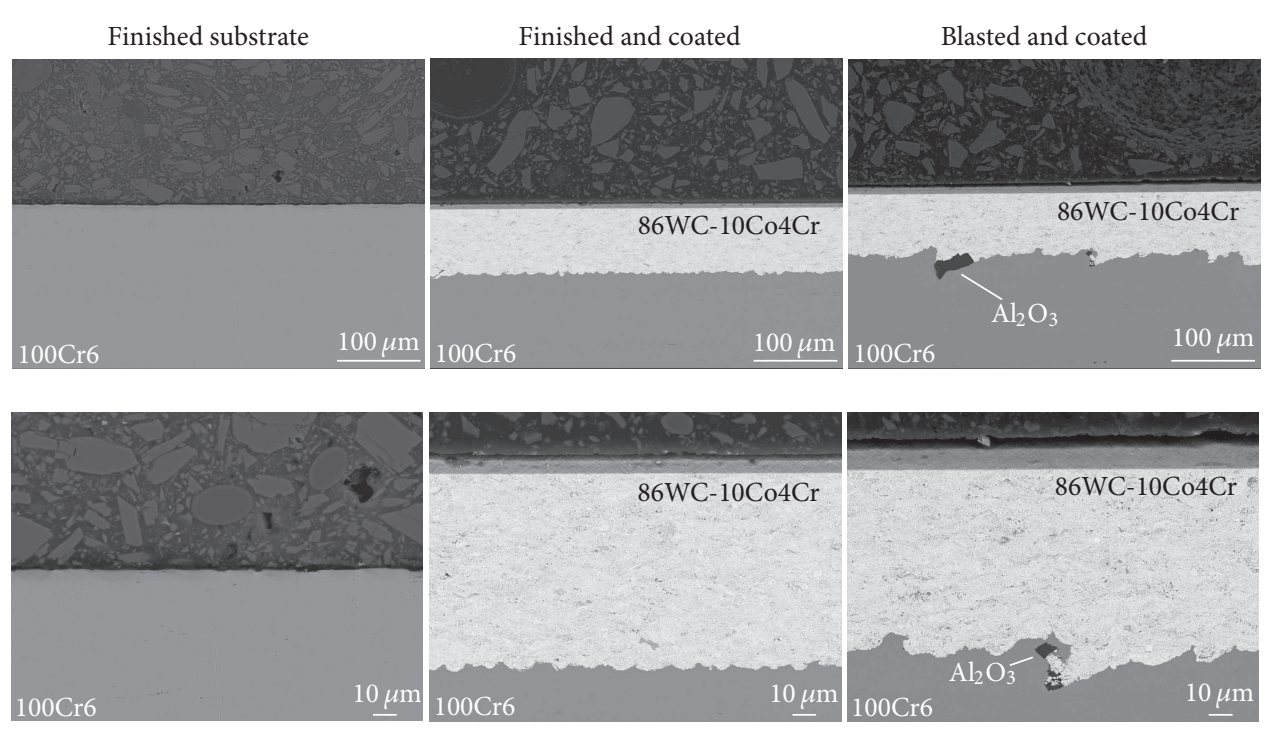

FIGURE 4: Interface between coating and substrate depending on the surface preparation.

Compared to this, a microfinishing process with only muddled finishing films is less aggressive and a smooth surface topography occurs. Even with premachining with a grain size of $d_{K}=30 \mu \mathrm{m}$, the mean roughness depth does not exceed $R z=0.7 \mu \mathrm{m}$. In case of using two subsequent finishing steps with smaller grain size $\left(d_{K}=9 ; 3 \mu \mathrm{m}\right)$, it is possible to decrease the mean roughness depth below $R z=$ $0.5 \mu \mathrm{m}$. Regarding the material ratio, there is no significant change in the relation between peak height and valley depth. Both are decreased homogeneously and the peak/valley relation stays at $R \mathrm{pk} / R \mathrm{vk}=0.3$.

Thus, by combining the mentioned properties of the finishing films in one process chain, it is possible to generate a smooth structure with little profile valleys or a plateau structure with a defined valley depth. Regarding slide faces, it often is better to have a plateau structure with defined profile valleys instead of a smoother surface without valleys. Moreover, also for coating substrates, it is necessary to provide a surface which supports a good adhesion between coating and substrate. In order to replace the conventionally used blasting process, a detailed description of the workpiece topography has to be made and further surface characteristics have to be considered. By using conventional machining processes like milling, grinding, and honing with the aim to structure the surface topography instead of just increasing the stock removal rate, the blasting process can be replaced.

First results concerning the quality of the interface between coating and substrate are shown in Figure 4. As shown on the left side, the originally finished steel surface is smooth and regular. With the subsequent tungsten carbide coating (in the middle of Figure 4), the smooth surface has been roughened through the kinetic energy of the powder particles. Nevertheless, the interface is characterized by a regular structure without cracks and failures. In contrast, the interface between the coating and the initial blasted surface is characterized by an irregular structure with several deeper grooves which are filled with particls from the blasting process. Such inhomogeneous grooves and material artifacts can act as crack initiators under specific loading situations. Thus, the interface between the steel substrate and the tungsten carbide coating can rather be improved by finishing the substrate compared to blasting the substrate.

\section{Machining of the Coated Surface}

In this study, the workpieces have been coated with fine WCCoCr powders with a particle size between 2 and $10 \mu \mathrm{m}$. The main advantages of these fine powders are the reduced porosity of less than 1 percent and a thin layer thickness of $100-140 \mu \mathrm{m}$. The surface roughness "as-sprayed" is also lower when using fine powders [15]. The quality of the coating "as-sprayed" has a mean roughness depth above $R z>10 \mu \mathrm{m}$. Regarding the subsequent DLC coating with a thickness of less than $5 \mu \mathrm{m}$, the "as-sprayed" condition does not provide the requirements for a good interface between tungsten carbide and DLC coating. In order to improve the surface quality, the workpieces were ground. Many studies outlined that a subsequent grinding process directly affects the tribological behaviour of the coating. On the one hand, there is an improved erosion resistance realized by compressive residual stresses which are induced into the surface by grinding [16-18]. On the other hand, in case of sliding contact, the decreased surface roughness leads to less friction and a lower wear level [19]. Furthermore, it has been shown that the wear rate of the DLC coating will significantly increase, if the substrate surface roughness exceeds the specific roughness value $R a>1 \mu \mathrm{m}$. This increase is based on a change in wear mechanisms [20]. Based on these findings, the approach in this study was to examine the influence of different process parameters like cutting speed, workspeed, and cutting depth on the resulting surface topography. To avoid several problems concerning surface cracking, which can occur in case of using CBN-wheels, only diamond grinding wheels were used in this study [21]. The 


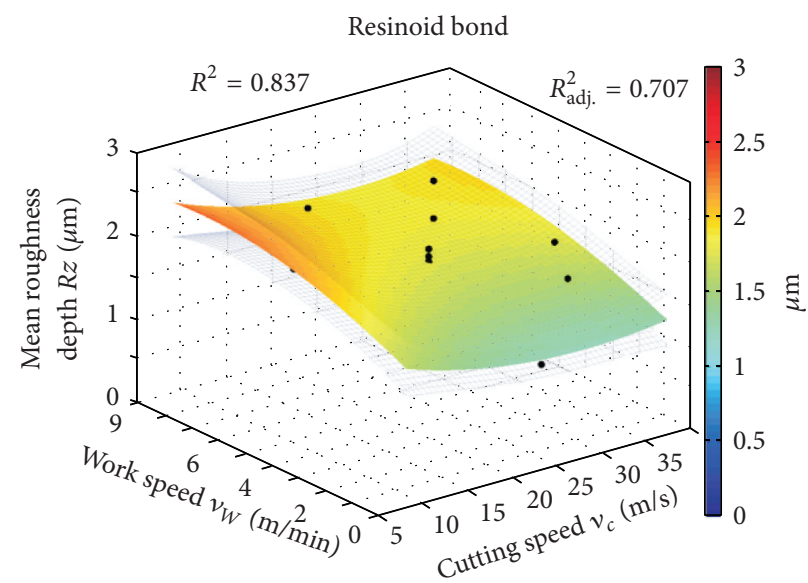

$\begin{array}{ll}\text { Grinding of 86WC-10Co-4Cr } & \\ \text { Grain type: } & \text { Diamond } \\ \text { Grain size: } & d_{K}=64 \mu \mathrm{m} \\ \text { Bond: } & \text { Resinoid, } \\ & \text { metallic, } \\ & \text { vitrified } \\ \text { Grain concentration: } & 75-125 \\ \text { Cutting depth: } & a_{e}=13 \mu \mathrm{m} \\ \text { Stock allowance: } & z=39 \mu \mathrm{m}\end{array}$
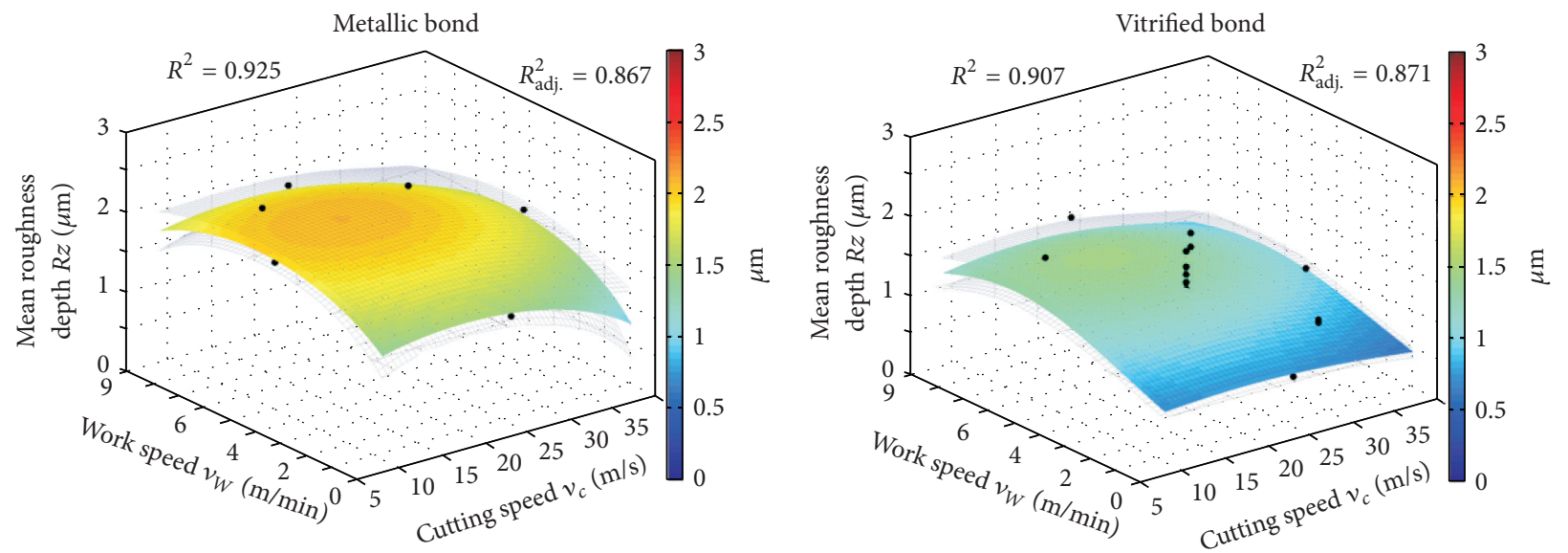

FIGURE 5: Grinding of the HVOF-coating-surface roughness.

grain size of $d_{K}=64 \mu \mathrm{m}$ was similar for all three grinding wheels. The wheels differed regarding the bond type and the grain concentration. As shown in Figure 5, it is possible to machine these coatings with all three bond types, although there are several differences regarding the surface roughness. Similar for all three grinding wheels, a better surface quality is achieved by using lower work speed. This effect is based on the fact that a lower workspeed is proportional to a decreased undeformed chip thickness. In case of having a decreased chip thickness, the surface roughness decreases as well [22]. The same effect occurs when increasing the cutting speed.

Beside the parameter value cutting speed and workspeed, the grain concentration has a significant influence on the surface quality. Based on the good damping properties, typically it is the resinoid bond which is responsible for high quality surfaces [22]. In this case, it is the bond type with the worst surface quality compared to the results achieved by a grinding wheel with metallic or vitrified bond. Additionally, there is a remarkable decrease in surface roughness by increasing the grain concentration. The reason for this functional relation is the dependence between the grain concentration and the undeformed chip thickness. By increasing the grain concentration, the chip thickness decreases and the same effect, as beforehand mentioned, occurs.

\section{Conclusion}

Summarizing we can conclude that, in this study, alternative machining processes were developed, in order to prepare a workpiece surface for a subsequent thermal coating process with tungsten carbide. Furthermore, the influence of different process parameters on grinding of the coated surface was examined. To avoid several disadvantages of a blasting process, which is usually used to activate the surface, a milling process and a short-stroke honing process were considered to achieve the needed surface structure. Based on their specific process kinematic, both processes are able to generate surface structures with variable material ratios. The preparation of the surface by honing especially was successful regarding the interface between the coating and the substrate. The interface between the honed substrate and the coating showed a regular structure opposite to the interface between the blasted substrate and the coating which is characterized by several deeper grooves and blasting particles. In order to achieve a smooth surface topography of the coated surface, the used grinding process was optimized regarding the specification of the diamond wheels and the relevant influencing variables. With this subsequent machining of the coating, the requirements for the use as a slide face or an optional subsequent DLC (Diamond Like Carbon) coating were achieved. 


\section{Acknowledgments}

The investigations and scientific results described in this paper were achieved in a special research project called Development of Nano-Encased Coating Materials and Tribologically Optimized Micro- and Nanostructured Multilayer High-Performance Coatings which was supported by the European Union (Europäischer Fonds für regionale Entwicklung) and the Ziel2.NRW initiative.

\section{References}

[1] T. N. Rhys-Jones, "Thermally sprayed coating systems for surface protection and clearance control applications in aero engines," Surface and Coatings Technology, vol. 43-44, no. 1, pp. 402-415, 1990.

[2] B. D. Sartwell and P. E. Bretz, "HVOF thermal spray coatings replace hard chrome," Advanced Materials and Processes, vol. 156, no. 2, pp. 25-28, 1999.

[3] R. Thorpe, H. Kopech, and N. Gagne, "HVOF thermal spray technology," Advanced Materials and Processes, vol. 157, no. 4, pp. 27-29, 2000.

[4] L. L. Boys, "Method for finishing thermal spray coatings", in Proceedings of the Thermal Spray Coating Conference, pp. 135-138, Long Beach, Calif, USA, 1984.

[5] R. B. Massad, "Diamond wheel grinding of thermal spray materials," in Proceedings of the Thermal Spray Conference, pp. 139-146, 1984.

[6] L. C. Casteletti, A. L. Neto, and G. E. Totten, "HVOF production of hard chromium substitution coatings for improved wear," Industrial Heating, vol. 75, no. 1, pp. 53-57, 2008.

[7] C. Rincón, G. Zambrano, A. Carvajal et al., “Tungsten carbide/ diamond-like carbon multilayer coating on steel for tribological applications," Surface and Coatings Technology, vol. 148, no. 2-3, pp. 277-283, 2001.

[8] A. Khellouki, J. Rech, and H. Zahouani, "Influence of the belt-finishing process on the surface texture obtained by hard turning," Proceedings of the Institution of Mechanical Engineers B, vol. 221, no. 7, pp. 1129-1137, 2007.

[9] A. Khellouki, J. Rech, and H. Zahouani, "The effect of abrasive grain's wear and contact conditions on surface texture in belt finishing," Wear, vol. 263, no. 1-26, pp. 81-87, 2007.

[10] M. Omar, "Finishbänder-Technologie und Einsatzmöglichkeiten," in Honen in Forschung und industrieller Anwendung, Qualität in der Fertigung, Fachtagung, Vulkan, 1995.

[11] K. U. Paffrath, T. Heymann, and D. Biermann, "Umweltfreundlicher Glanz," WB Werkstatt und Betrieb, vol. 143, pp. 62-64, 2010.

[12] D. M. Schibisch, "Kühles Band für beste Güte," Automobil Industrie, vol. 44, no. 10, pp. 84-88, 1999.

[13] G. Rudloff, "Der superfinish-prozess-superfinish-bearbeitung mit band," Moderne Schleiftechnologie und Feinstbearbeitung, pp. 10-1-1019, 2004.

[14] G. Rudloff, Superfinish von Automobil-Komponenten Mit Band, Spanende Fertigung Prozesse, Innovationen, Werkstoffe, Vulkan, Essen, Germany, 5th edition.

[15] W. Tillmann, M. Tolan, P. Hollingsworth, L. Baumann, and M. Paulus, "Nanostructured WC-Co coatings manufactured by fine powders $(-10+2 \mu \mathrm{m})$ with ultra-fine carbides $(400 \mathrm{~nm})$ by means of HVOF," in Proceedings of the International Thermal Spray Conference \& Exposition, Hamburg, Germany, 2011.
[16] J. K. N. Murthy, D. S. Rao, and B. Venkataraman, "Effect of grinding on the erosion behaviour of a WC-Co-Cr coating deposited by HVOF and detonation gun spray processes," Wear, vol. 249, no. 7, pp. 592-600, 2001.

[17] B. Zhang, X. Liu, C. A. Brown, and T. S. Bergstrom, "Microgrinding of nanostructured material coatings," CIRP Annals-Manufacturing Technology, vol. 51, no. 1, pp. 251-254, 2002.

[18] Z. H. Deng, B. Zhang, and F. Cheng, "Investigations of grinding forces for nanostructured WC/12Co coatings," Key Engineering Materials, vol. 304-305, pp. 151-155, 2006.

[19] K. Bonny, P. De Baets, J. Quintelier et al., "Surface finishing: Impact on tribological characteristics of WC-Co hardmetals," Tribology International, vol. 43, no. 1-2, pp. 40-54, 2010.

[20] J. Jiang and R. D. Arnell, "The effect of substrate surface roughness on the wear of DLC coatings," Wear, vol. 239, no. 1, pp. 1-9, 2000.

[21] Z. Zhong, "Machining of thermally sprayed WC-Co coatings," Materials and Manufacturing Processes, vol. 16, no. 1, pp. 103-112, 2001.

[22] F. Klocke and W. König, Fertigungsverfahren 2. Schleifen, Honen, Läppen, Springer, Berlin, Germany, 4th edition, 2005. 

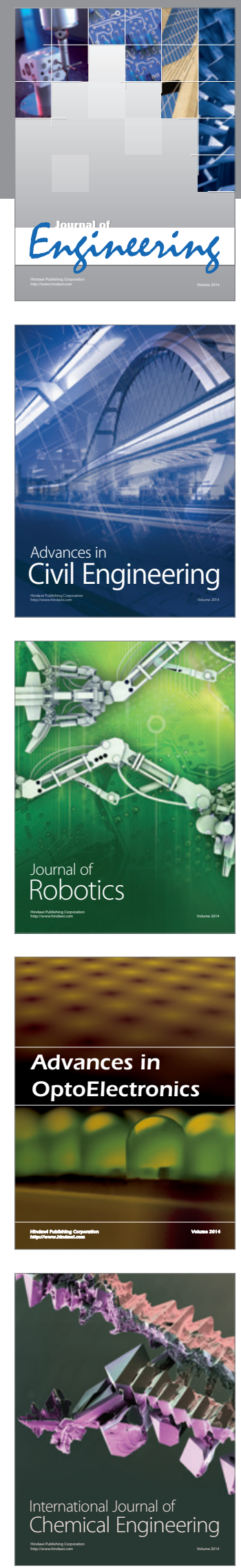

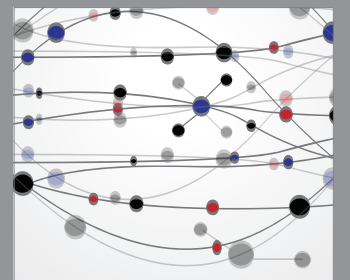

The Scientific World Journal
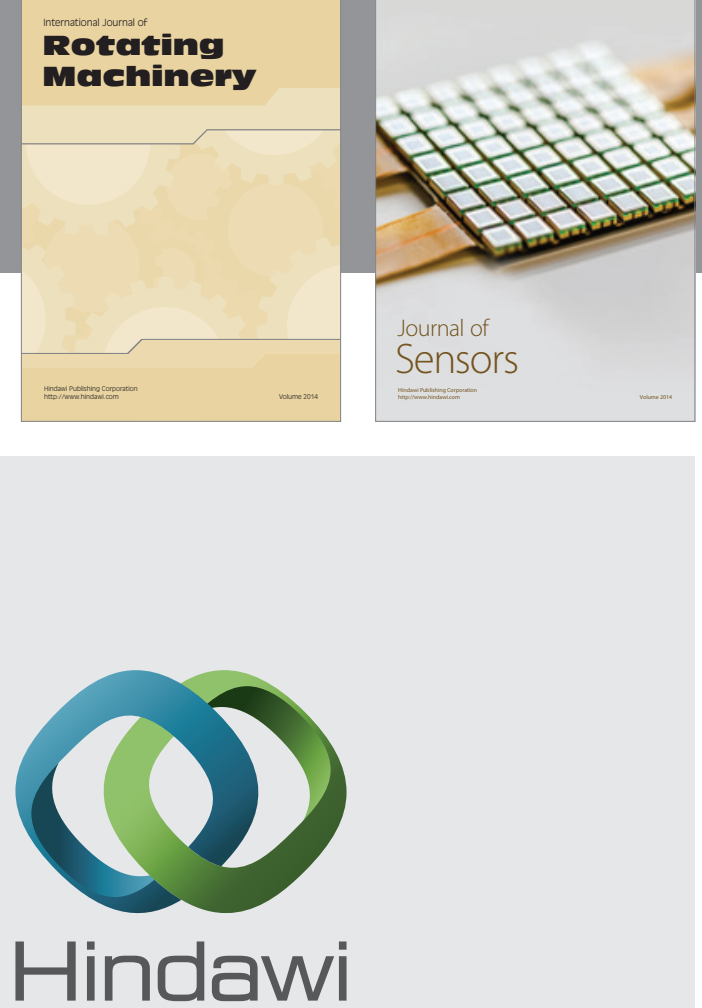

Submit your manuscripts at http://www.hindawi.com
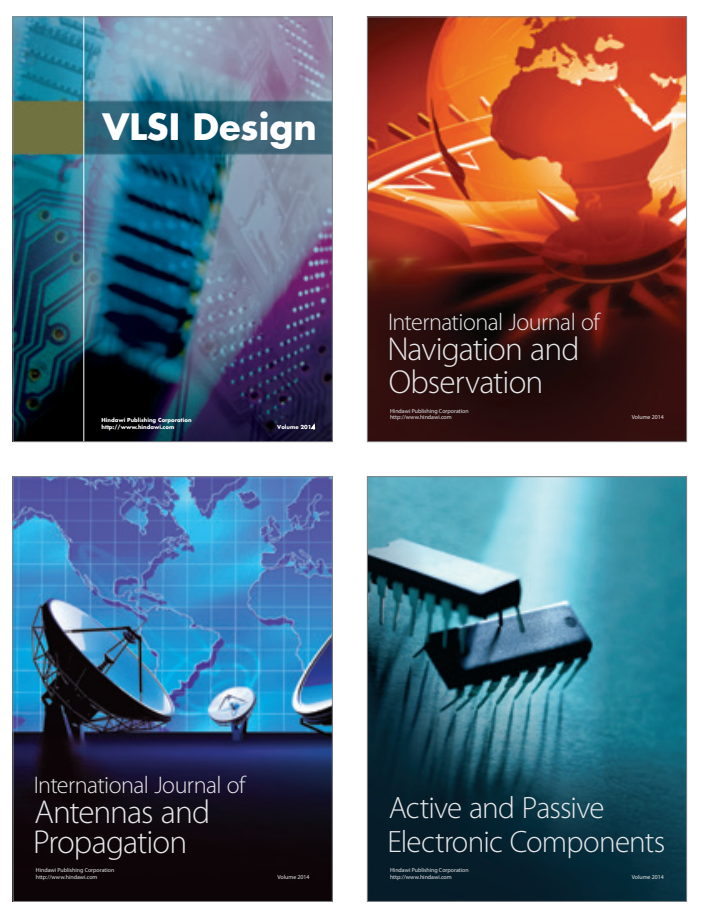
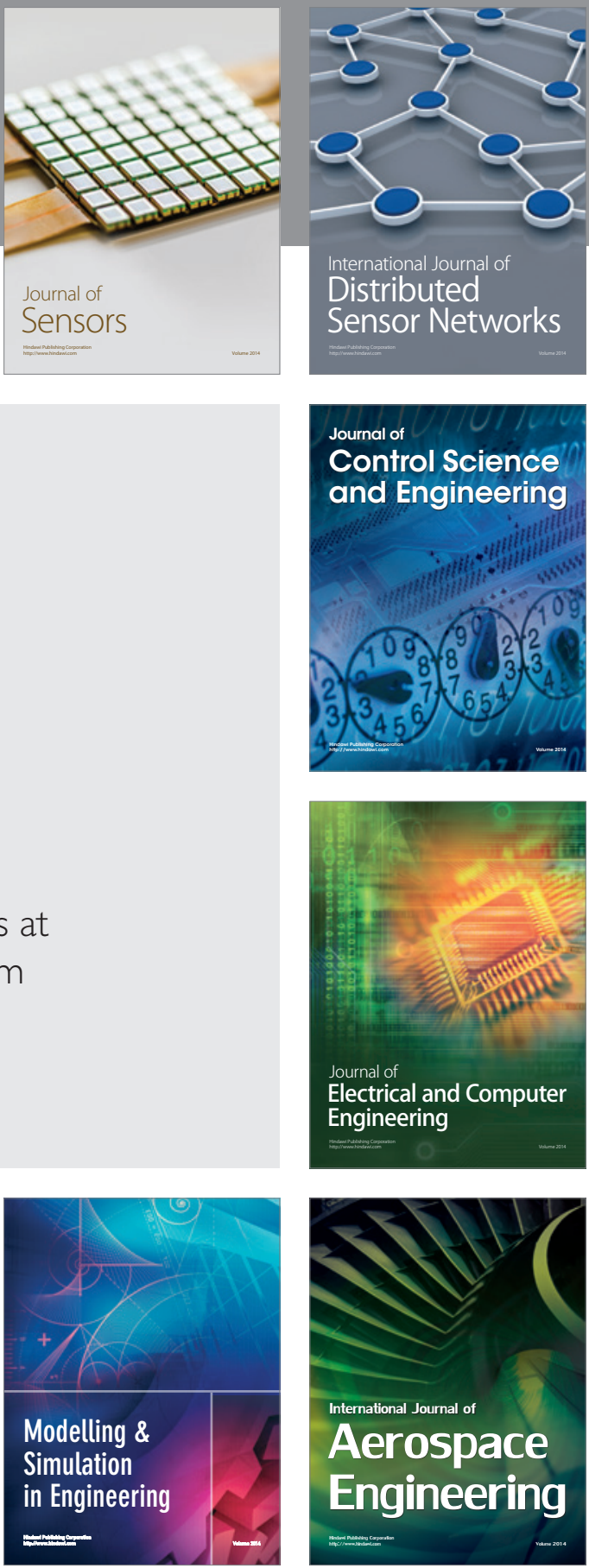

Journal of

Control Science

and Engineering
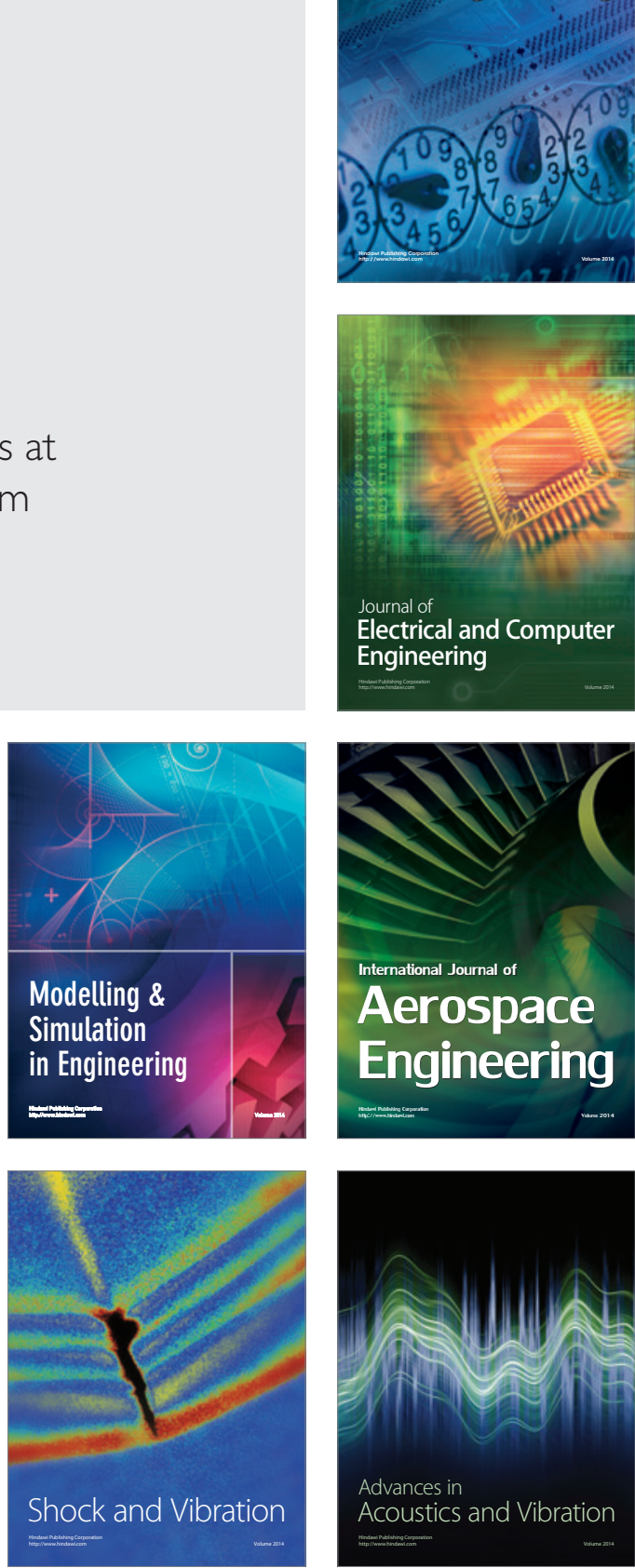